To appear in

Proc. of the Eighth Int'l Symposium on Silicon Materials Science and Technology edited by H. Huff, U. Gösele, and H. Tsuya

(The Electrochemical Society, Pennington, NJ, 1998).

\title{
Boron-enhanced diffusion of boron from ultralow-energy boron implantation.
}

A. Agarwal, D. J. Eaglesham, H.-J. Gossmann, L. Pelaz, S. B. Herner, D. C. Jacobson

Bell Laboratories, Lucent Technologies, Murray Hill, New Jersey, 07974

T. E. Haynes

Solid State Division, Oak Ridge National Laboratory, Oak Ridge, Tennessee 37831

Yu. E. Erokhin

Eaton Corporation, 55 Cherry Hill Drive, Beverly, Massachusetts 01915

"The submitted manuscript has been authored by a contractor of the US Government under contract No. DEAC05-960R22464. Accordingly, the US Government retains a nonexclusive, royalty-free license to publish or reproduce the published form of this contribution, or allow others to do so, for US Government purposes."

Prepared in collaboration with

Oak Ridge National Laboratory

Oak Ridge, Tennessee 37831

Managed by

LOCKHEED MARTIN ENERGY RESEARCH CORP.

for the

U.S. DEPARTMENT OF ENERGY

wder contract DE-AC05-96OR22464.

January 1998 


\section{DISCLAIMER}

This report was prepared as an account of work sponsored by an agency of the United States Government. Neither the United States Government nor any agency thereof, nor any of their employees, makes any warranty, express or implied, or assumes any legal liability or responsibility for the accuracy, completeness, or usefulness of any information, apparatus, product, or process disclosed, or represents that its use would not infringe privately owned rights. Reference herein to any specific commercial product, process, or service by trade name, trademark, manufacturer, or otherwise does not necessarily constitute or imply its endorsement, recommendation, or favoring by the United States Government or any agency thereof. The views and opinions of authors expressed herein do not necessarily state or reflect those of the United States Government or any agency thereof. 


\title{
BORON-ENHANCED-DIFFUSION OF BORON FROM ULTRA-LOW-ENERGY BORON IMPLANTATION
}

\author{
Aditya Agarwal ${ }^{*} 1,2$, D. J. Eaglesham1, H.-J. Gossmann ${ }^{1}$, L. Pelaz ${ }^{1}$, S. B. Herner ${ }^{1}$, \\ D. C. Jacobson ${ }^{1}$, T. E. Haynes ${ }^{2}$, and Yu. E. Erokhin ${ }^{3}$ \\ ${ }^{1}$ Bell Laboratories, Lucent Technologies, Murray Hill NJ 07974 \\ 2Solid State Division, Oak Ridge National Laboratory, Oak Ridge, TN 37831 \\ ${ }^{3}$ Eaton Corporation, 108 Cherry Hill Drive, Beverly MA 01915 \\ *Present address: Eaton Corporation, 55 Cherry Hill Drive, Beverly MA 01915; \\ E-mail: aagarwal@bev.etn.com
}

\begin{abstract}
We have investigated the diffusion enhancement mechanism of BED (boron-enhanced-diffusion), wherein the boron diffusivity is enhanced three to four times over the equilibrium diffusivity at $1050^{\circ} \mathrm{C}$ in the proximity of a silicon layer containing a high boron concentration. It is shown that BED is associated with the formation of a fine-grain polycrystalline silicon boride phase within an initially amorphous Si layer having a high $\mathrm{B}$ concentration. For $0.5 \mathrm{keV} \mathrm{B}^{+}$, the threshold implantation dose which leads to BED lies between $3 \times 10^{14}$ and of $1 \times 10^{15} \mathrm{~cm}^{-2}$. Formation of the shallowest possible junctions by $0.5 \mathrm{keV} \mathrm{B}^{+}$requires that the implant dose be kept lower than this threshold.
\end{abstract}

\section{INTRODUCTION}

It is currently projected that $0.07 \mu \mathrm{m}$ technology will require junction depths, $x_{j}$, $\approx 30 \mathrm{~nm}$ (1). This places severe restrictions on the amount of enhanced diffusion which can be tolerated if dopants are to be introduced by ion implantation. We recently demonstrated that transient enhanced diffusion (TED) of $\mathrm{B}$ marker layers from $\mathrm{Si}^{+}$ implants is virtually eliminated at ultra-low-energies (ULE) of $1 \mathrm{keV}$ or less (2). This reduction is both expected and easily understood if the surface is considered to be a sink for interstitials. In that case, the closer the implantation-induced excess interstitials are located to the surface the fewer hops they will make before reaching the surface and being annihilated (2). Since boron diffusion is mediated by interstitials, the diffusivity enhancement is proportional to the total number of interstitial hops during annealing and thus decreases as well (2). The initial assumption that the surface is a perfect sink has 
also been verified by comparing experimental data with Monte-Carlo and continuum simulations for different surface-sink conditions (2).

In the case of $\mathrm{B}^{+}$implants however, enhanced diffusion is observed at energies as low as $0.5 \mathrm{keV}$ (3). This diffusion enhancement, which is in addition to the standard concentration dependence (4), is observed even from evaporated B layers and has been called BED, or boron-enhanced-diffusion (3). In this paper, we further investigate the BED phenomenon. We demonstrate that BED is driven by interstitials produced during annealing of the boron-containing silicon layer when the boron dose exceeds a threshold that corresponds to both amorphization during implantation and silicon boride phase formation during annealing. We also discuss the limit on ULE $\mathrm{B}^{+}$implant doses which is implied by these findings.

\section{EXPERIMENTAL AND RESULTS}

Enhanced diffusion has been quantified using the method of embedded B marker layers

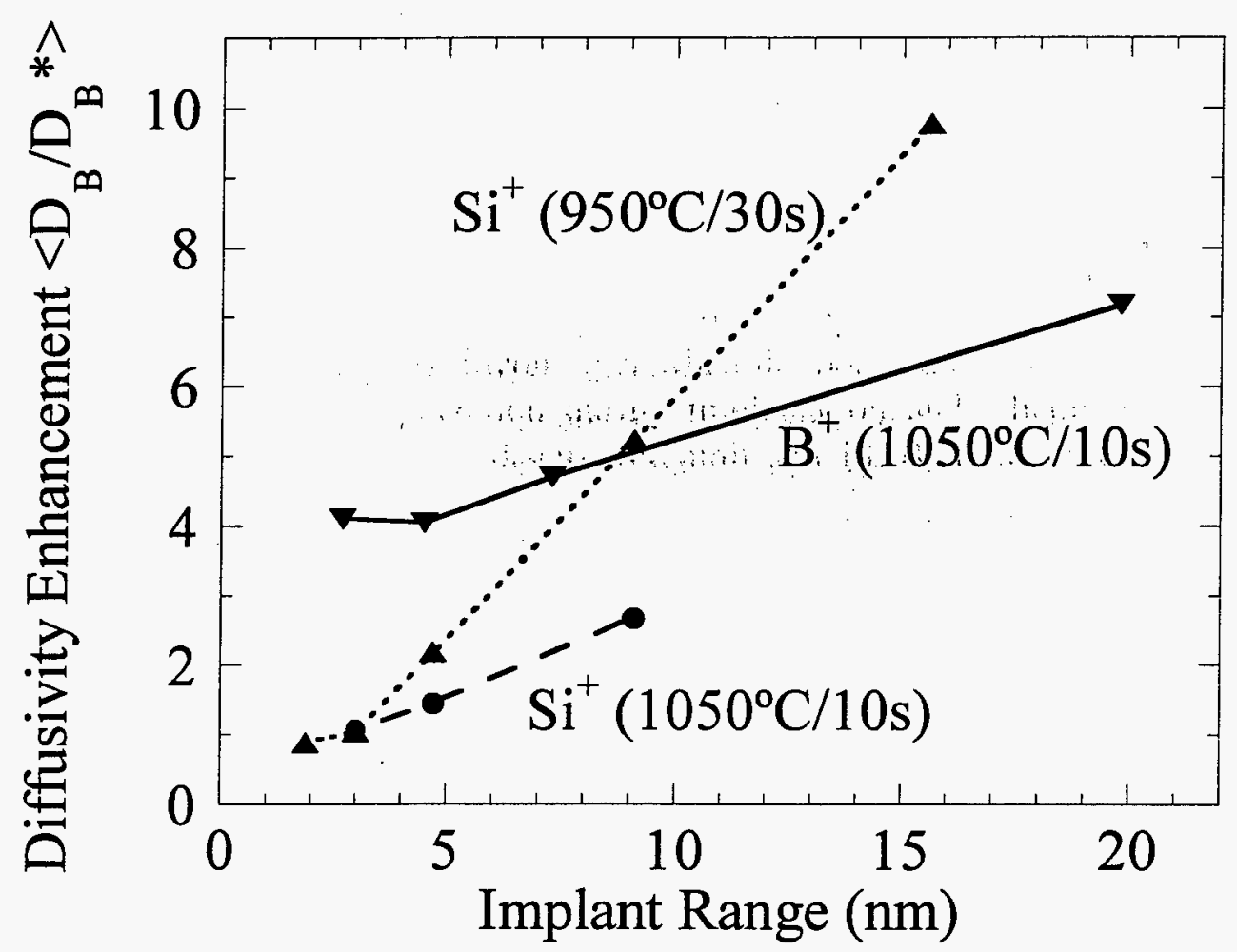

Figure 1. Summary of diffusivity enhancement data for $\mathrm{ULE} \mathrm{Si}^{+}$and $\mathrm{B}^{+}$implants from References 1 and 2, respectively. The $\mathrm{Si}^{+}$dose of $10^{14} / \mathrm{cm}^{2}$ was implanted at $0.5,1$, 2,5 or $10 \mathrm{keV}$ for $950^{\circ} \mathrm{C} / 30 \mathrm{~s}$ annealing, or at 1,2 , and $5 \mathrm{keV}$ for $1050^{\circ} \mathrm{C} / 10 \mathrm{~s}$ annealing; The $\mathrm{B}^{+}$dose of $10^{15} / \mathrm{cm}^{2}$ was implanted at $0.5,1,2$, and 5 for $1050^{\circ} \mathrm{C} / 10 \mathrm{~s}$ annealing. 


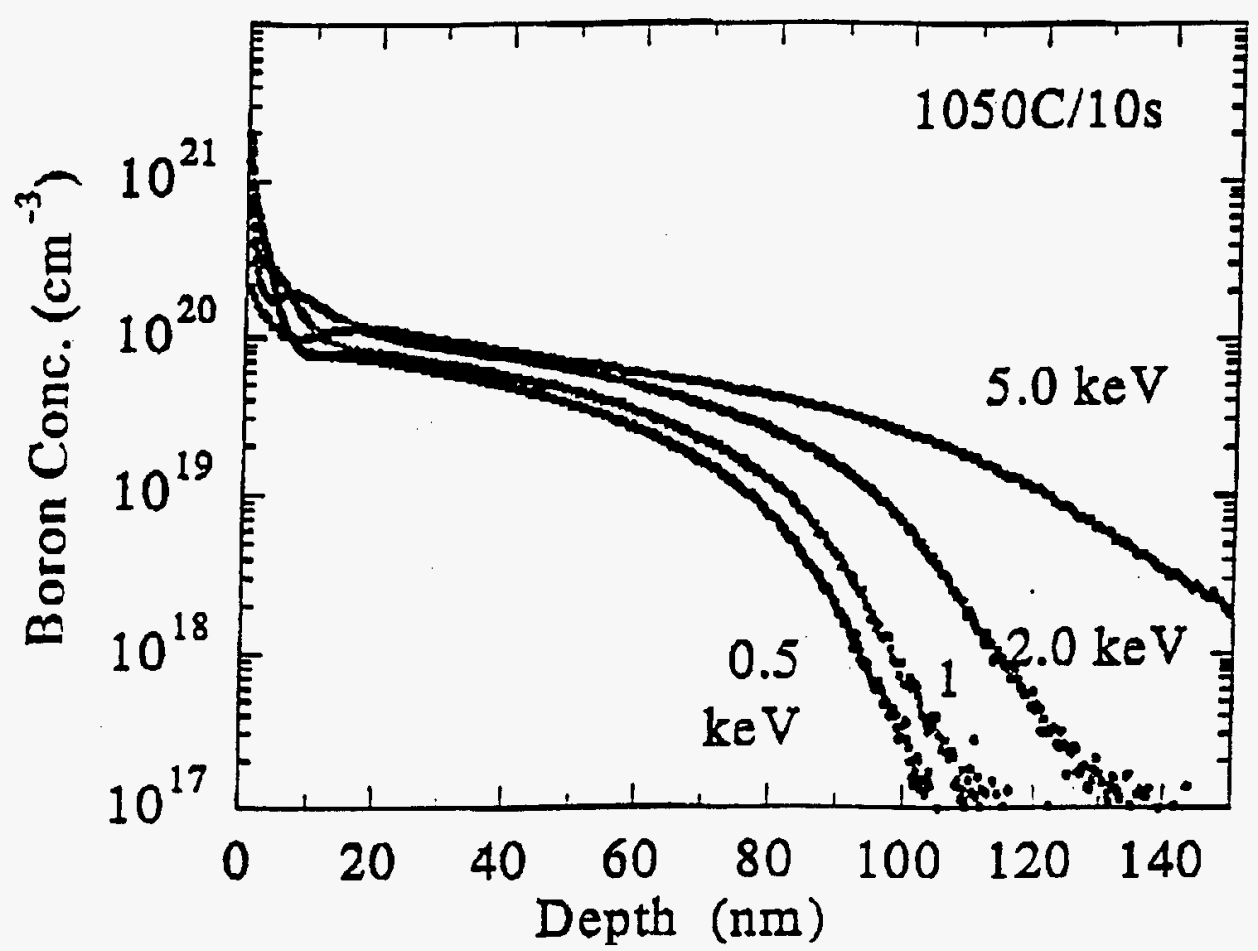

Figure 2. SIMS profiles comparing diffusion of $1 \times 10^{15} \mathrm{~cm}^{-2} \mathrm{~B}$ implanted at 5, 2, 1, and $0.5 \mathrm{keV}$ at from $1050^{\circ} \mathrm{C} / 10 \mathrm{~s}$ annealing (After Ref.3).

grown by molecular-beam-epitaxy (MBE) (5). In this way the detecting marker is spatially separated from the source of interstitials allowing the diffusivity enhancement and hence the interstitial supersaturation to be quantified unambiguously. The diffusivity enhancement is defined as the time averaged ratio of the observed boron diffusivity, $D_{B}$, to the thermal equilibrium diffusivity, $D_{B}{ }^{*}$. A value of $1 \times$ means no enhancement. Furthermore, since $B$ diffusion in silicon is mediated by interstitials, the value of $D_{B} / D_{B}{ }^{*}$ also gives the supersaturation ratio of the interstitial concentration relative to its equilibrium value. A value greater than 1 implies interstitial injection.

Figure 1 illustrates the reduction in TED at 950 and $1050^{\circ} \mathrm{C}$ which accompanies a reduction in the implantation energy down to $0.5 \mathrm{keV}$ for a fixed $\mathrm{Si}^{+}$dose of $1 \times 10^{14} \mathrm{~cm}^{-2}$. Each data point corresponds to the diffusivity enhancement measured at a buried marker located $150 \mathrm{~nm}$ below the surface during annealing following $\mathrm{Si}^{+}$ implantation at energies ranging from 10 to $0.5 \mathrm{keV}$ (2). The data has intentionally been plotted as a function of the projected ion range corresponding to the implantation energy to illustrate the linear dependence of diffusivity enhancement on the distance of the implantation-induced excess interstitials to the surface. From a simple random walk argument the total number of hops made by an interstitial before arriving at the surface is a quadratic function of its initial distance from the surface. Under conditions of perfect 


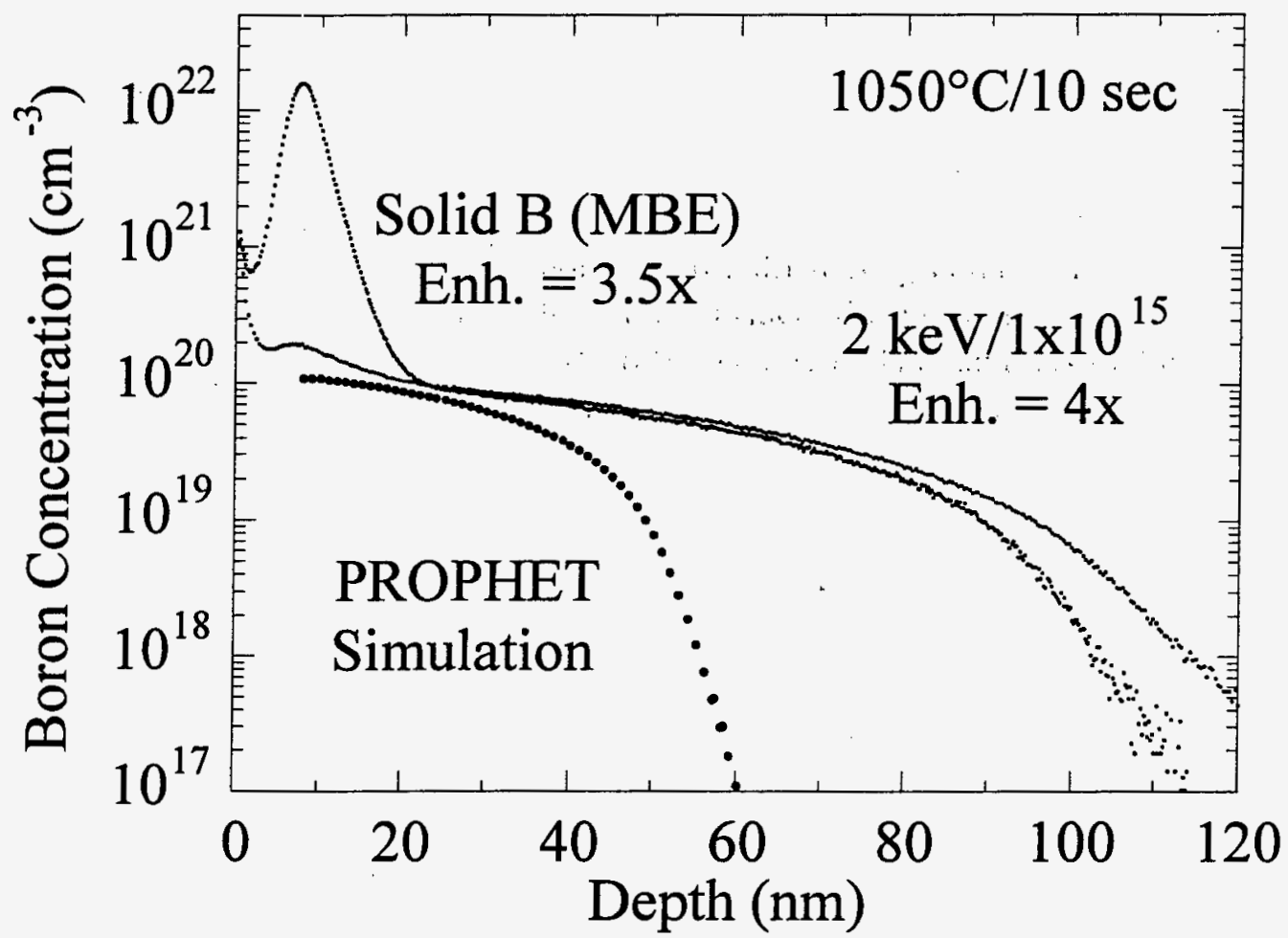

Figure 3. SIMS profiles comparing diffusion from an evaporated pure-B layer (capped with $10 \mathrm{~nm}$ of amorphous Si) with that from a $1 \times 10^{15} \mathrm{~cm}^{-2}, 2 \mathrm{keV} \mathrm{B}$ implant, after $1050^{\circ} \mathrm{C} / 10 \mathrm{~s}$ annealing. Also shown for comparison is a simulated diffusion profile which assumes only the standard concentration-dependent diffusivity.

recombination at the surface (every interstitial is annihilated the very first time it reaches the surface), the diffusivity enhancement, related to the number of interstitial hops per lattice site, is then expected to have a linear dependence on $R_{I}$. Such a linear dependence is observed both 950 and $1050^{\circ} \mathrm{C}(2)$.

Figure 1 also shows diffusivity enhancements extracted from the profiles shown in Fig. 2 for a fixed $\mathrm{B}^{+}$dose of $1 \times 10^{15} \mathrm{~cm}^{-2}$, implanted at $5,2,1$, and $0.5 \mathrm{keV}$, and annealed at $1050^{\circ} \mathrm{C}$ for $10 \mathrm{~s}$. In contrast to the reduction in enhancement to $1 \times$ observed for ULE $\mathrm{Si}^{+}$, a saturation in the reduction of diffusivity enhancement at $4 \times$ is seen for $\mathrm{B}^{+}$ implanted at 1 and $0.5 \mathrm{keV}$ (Fig.1). Extrapolation of this trend predicts that enhanced diffusion would be observed even if the implantation energy was reduced to a few $\mathrm{eV}$ ! To establish that the trend exhibited by the $\mathrm{B}^{+}$data can be extrapolated to extremely low energies, we tested for a diffusivity enhancement from an evaporated surface $B$ layer. Evaporated B represents the ultimate limit of ULE implantation since the B atoms arrive at the surface with energies of the order of $\approx 0.0001 \mathrm{keV}$, insufficient for Frenkel-pair defect generation. Figure 3 compares diffusion from an evaporated $B$ layer and from the $1 \times 10^{15} \mathrm{~cm}^{-2}, 2 \mathrm{keV} \mathrm{B}+$-implanted layer shown in Fig.2. The junction depth in the two samples is surprisingly similar even though the evaporated-B sample does not contain 


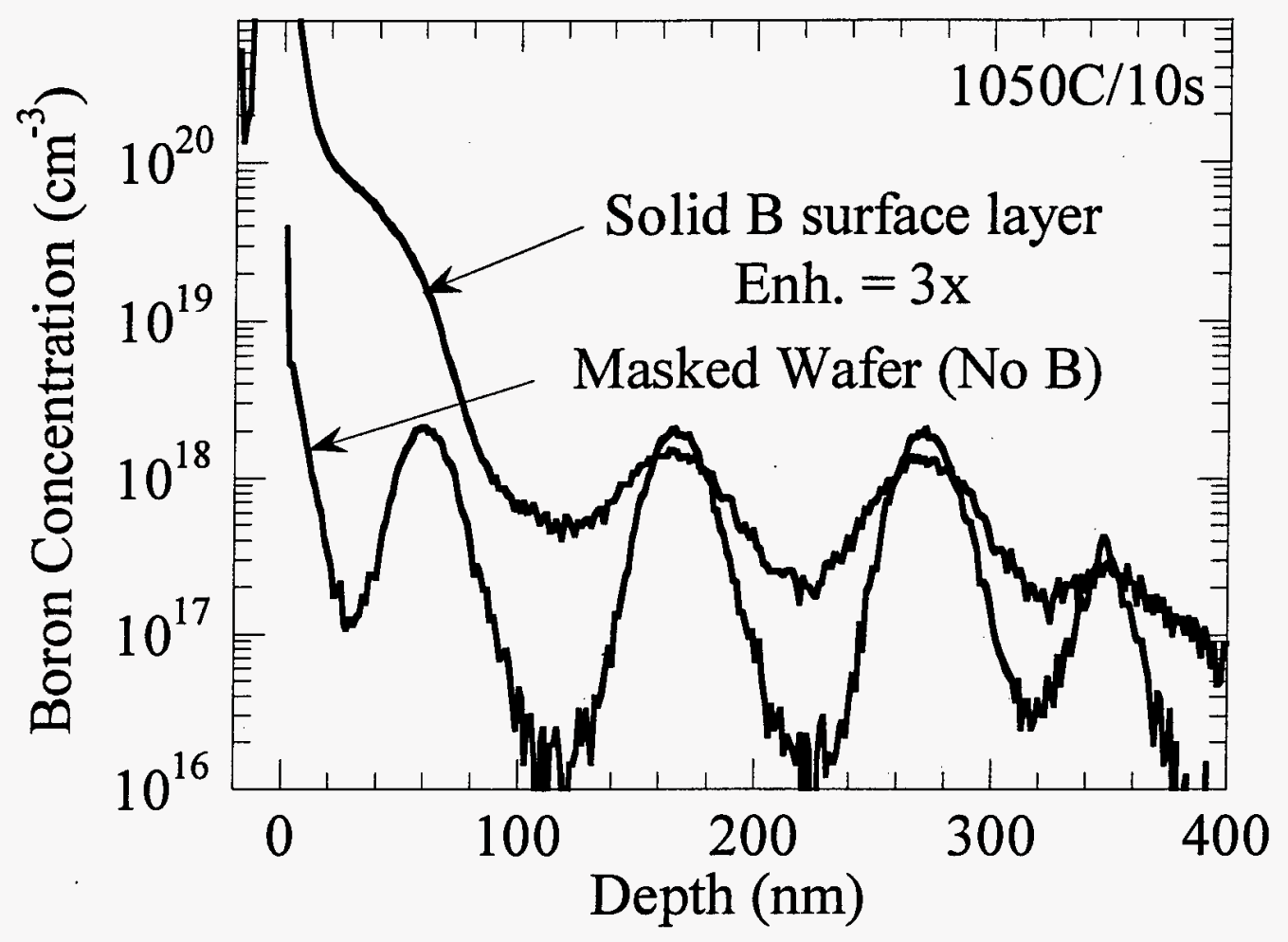

Figure 4. SIMS profiles comparing diffusion of B markers with and without a layer of pure-B on the surface.

any implant damage which could lead to TED. The enhancement for evaporated B is $3.5 \times$.

The observation of enhanced diffusion for evaporated B suggests that there is another source of interstitials in the sample with evaporated B. This hypothesis was directly confirmed using MBE-grown boron markers separated from an evaporated surface boron layer. Figure 4 compares diffusion of boron markers in samples with and without a pure B layer on the surface. It is clear from the data in Fig.4 that marker diffusion is enhanced in the sample with the surface B. This implies that the surface B layer produces an interstitial supersaturation in the near-surface bulk during annealing. Evaporated surface layers containing $10 \% \mathrm{~B}$ and $1 \% \mathrm{~B}$ were also grown on marker layer samples for comparison with the $100 \%$ B layer. The same enhancement was observed for the $10 \% \mathrm{~B}$ layer as for the $100 \% \mathrm{~B}$ surface layer, but there was no enhancement for the layer containing only 1\% B (Fig.5), indicating (a) that there exists a threshold concentration for the BED effect and (b) that the enhancement factor is independent of the boron concentration above this threshold (6). It should also be noted that the evaporated layer containing 1\% B grew epitaxially, as indicated by in situ RHEED, while the layers with larger $B$ concentrations were amorphous. 


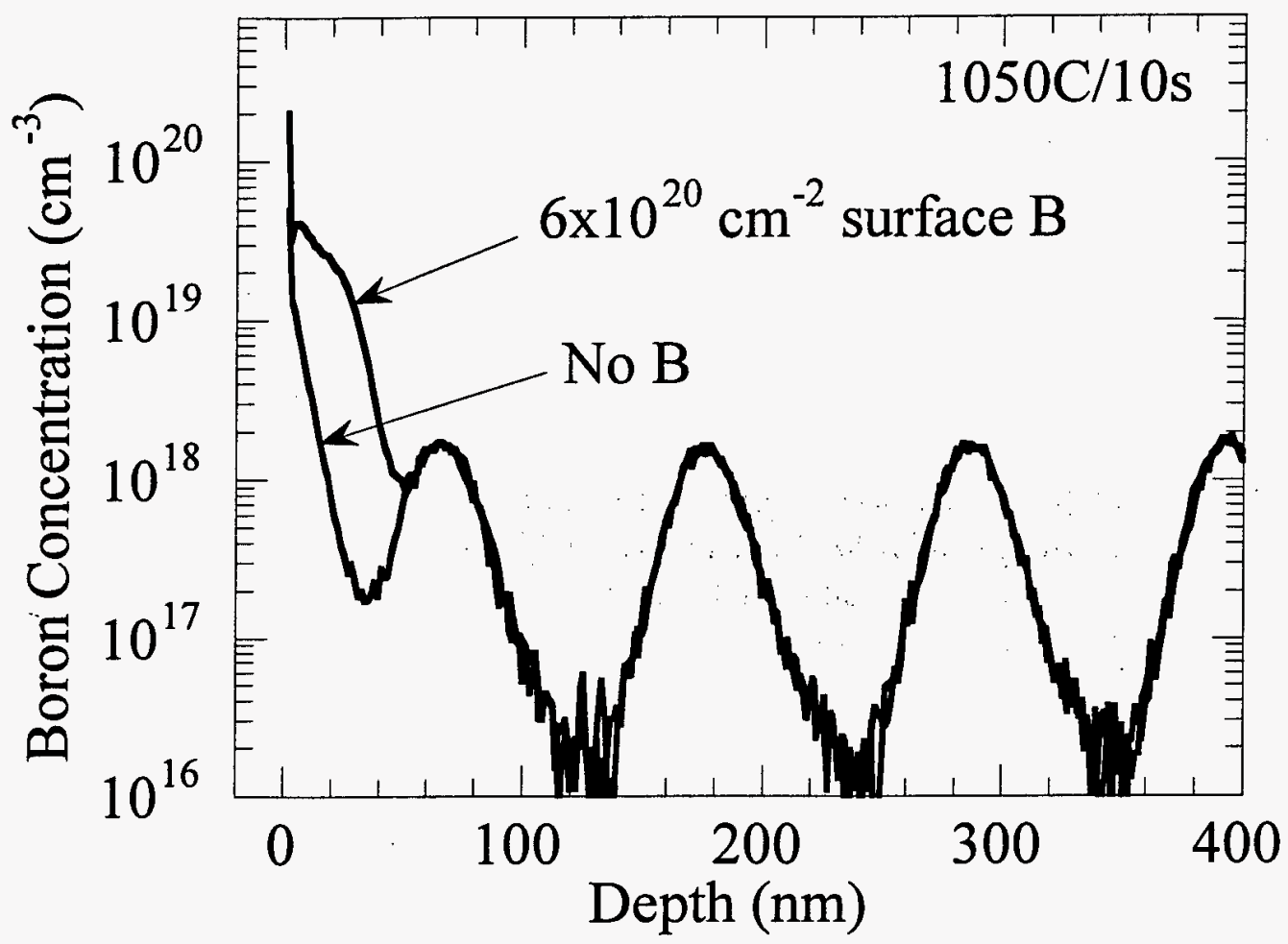

Figure 5. SIMS profiles comparing diffusion of $\mathrm{B}$ markers with and without $6 \times 10^{20}$ $\mathrm{cm}^{-3} \mathrm{~B}$ on the surface.

A threshold concentration is also observed in the case of implanted $\mathrm{B}^{+}$. Figure 6 shows diffusivity enhancement data from $0.5-\mathrm{keV} \mathrm{B}^{+}$as a function of implanted dose. As before, each data point corresponds to the enhancement at a boron marker located 150 $\mathrm{nm}$ below the surface following implantation at doses from $1 \times 10^{13}$ to $2 \times 10^{15} \mathrm{~cm}^{-2}$, and $10 \mathrm{~s}$ annealing at $1050^{\circ} \mathrm{C}$. The diffusivity enhancements from doses of $3 \times 10^{14} \mathrm{~cm}^{-2}$ and below are close to 1 (no enhancement), consistent with the reduced TED expected due to the very shallow placement of the implant damage. However, between the doses of $3 \times 10^{14}$ and $1 \times 10^{15} \mathrm{~cm}^{-2}$, the diffusivity enhancement abruptly increases from approximately $1 \times$ to $4 \times$. This increase is due to the onset of the BED effect and the enhancement factor of $4 x$ is consistent with that observed for evaporated B. According to TRIM simulations (7), the peak B concentrations corresponding to the two doses that bracket the increase in enhancement are $1 \%$ and $3 \%$. This threshold is also consistent with the evaporated-B threshold concentration of between 1 and $10 \%$.

\section{DISCUSSION}

It was previously shown that fairly modest $\mathrm{B}^{+}$doses can amorphize the implanted layer at ULE energies, e.g. between 2 and $5 \times 10^{15} \mathrm{~cm}^{-2}$ at $2 \mathrm{keV}$ (8). Moreover, once 


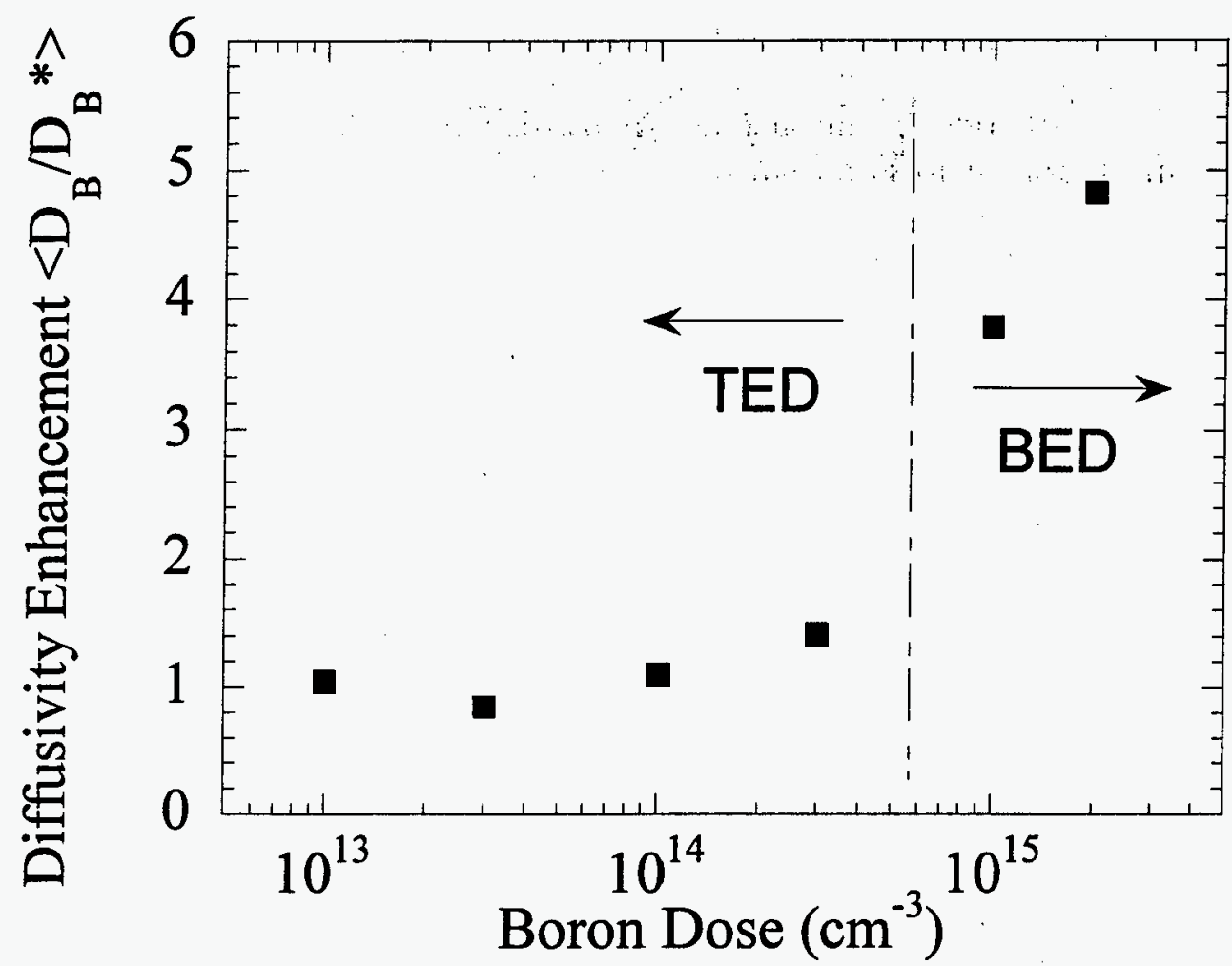

Figure 6. Diffusivity enhancement from $0.5 \mathrm{keV} \mathrm{B}^{+}$implanted at doses from $10^{13}$ to $2 \times 10^{15} \mathrm{~cm}^{-2}$.

amorphized by $\mathrm{B}^{+}$, the implanted layer does not regrow as crystalline $\mathrm{Si}$ during annealing. Instead, a fine-grain polycrystalline silicon boride phase, identified as $\mathrm{SiB}_{4}$, is formed (8). The concentrations of implanted B corresponding to the threshold doses for amorphization in that work were estimated to be between $2 \%$ and $10 \%$, i.e., similar to the threshold concentration for BED. From these observations, we conclude that the formation of a silicon boride phase in the high boron-concentration silicon layer injects interstitials into the bulk resulting in BED.

It is important to determine precisely what processing conditions lead to BED. There are two physical processes which precede the observation of BED in all of our experiments: creation of an amorphous silicon layer containing a high concentration of boron (either by implantation or by evaporation), and transformation of this amorphous silicon layer to a silicon boride phase during annealing. Strictly speaking, it is possible that both amorphization by boron implantation and the silicon boride phase transformation require different threshold boron doses. In the range of our experiments however, silicon boride phase transformation has only been observed when the layer was initially amorphous, and the two processes appear to have the same threshold. The formation of silicon boride in crystalline silicon has been studied previously by Armigliato, et al. (9). That work showed that precipitation of a silicon boride phase from boron-supersaturated polycrystalline silicon is quite slow, requiring several tens of hours, 
even at temperatures as high as $1000^{\circ} \mathrm{C}(9)$. In contrast, we have observed the formation of silicon boride in amorphized silicon within $10 \mathrm{~s}$ at $1050^{\circ} \mathrm{C}$. This relatively rapid transformation suggests that the kinetic barrier to silicon boride phase formation may be considerably reduced in amorphous silicon as opposed to crystalline silicon. This would provide a natural explanation for our observation that the threshold concentrations for boride phase formation and amorphization coincide. In other words, due to the slow kinetics of the boride phase transformation in crystalline silicon, the boride phase will form during typical anneals if and only if the implanted silicon layer is amorphous.

The implication of these findings for ultra-shallow junction formation is apparent: at ULE energies the $\mathrm{B}^{+}$implant dose needs to be smaller than that which will result in amorphization of the implanted layer in order to avoid silicon boride phase formation and $\mathrm{BED}$. We have estimated the threshold doses to achieve amorphization by $\mathrm{B}^{+}$ion implantation from a dose-dependence study at $0.5,2$, and $10 \mathrm{keV}$. At 2 and $10 \mathrm{keV}$ the amorphization threshold doses were between 2 and $5 \times 10^{15} \mathrm{~cm}^{-2}$ and 0.8 and $1 \times 10^{16} \mathrm{~cm}^{-2}$, respectively. At $0.5 \mathrm{keV}$ the amorphization dose was confirmed to be between $3 \times 10^{14}$ and $1 \times 10^{15} \mathrm{~cm}^{-2}$ by cross-section transmission electron microscopy. Clearly, the onset of BED corresponds to this threshold (Fig.5). For doses which exceed this threshold, the $4 \times$ diffusivity enhancement characteristic of $\mathrm{BED}$ at $1050^{\circ} \mathrm{C}$ means a disastrous doubling of the minimum $x_{j}$.

\section{SUMMARY}

We have investigated the diffusion enhancement mechanism, BED (boronenhanced-diffusion), where boron diffusion is enhanced in the proximity of a highconcentration boron-containing layer during annealing. We have shown that the phenomenon is related to the formation of a fine-grain silicon boride phase when annealing an amorphous $\mathrm{Si}$ layer which contains a high $\mathrm{B}$ concentration. Formation of the silicon boride phase results in injection of interstitials into the silicon bulk. These excess interstitials enhance boron diffusion. The threshold B dose for the BED effect coincides with the amorphization threshold dose. At $0.5 \mathrm{keV}$ : the threshold implantation dose which leads to BED lies between $3 \times 10^{14}$ and $1 \times 10^{15} \mathrm{~cm}^{-2}$. : Formation of the shallowest possible junctions by ULE $0.5 \mathrm{keV} \mathrm{B}^{+}$requires that the implant dose be kept lower than this threshold.

\section{ACKNOWLEDGEMENTS}

This research was supported in part by the U. S. Department of Energy, Office of Energy Research, Laboratory Technology Division under contract DE-AC05-96OR22464 with Lockheed Martin Energy Research Corp. and by Oak Ridge Associated Universities under contract DE-AC05-76OR00033. 


\section{REFERENCES}

1. National Technology Roadmap for Semiconductors (Semiconductor Industry Association, San Jose, 1995).

2. Aditya Agarwal, H.-J. Gossmann, D. J. Eaglesham, L. Pelaz, D. C. Jacobson, T. E. Haynes, and Yu. E. Erokhin, Appl. Phys. Lett. 71 (21), 3141 (1997).

3. Aditya Agarwal, H.-J. Gossmann, D. J. Eaglesham, L. Pelaz, S. B. Herner, D. C. Jacobson, T. E. Haynes, Tu. E. Erokhin, and R. Simonton, IEDM Tech. Digest., 467 (1997).

4. R. B. Fair and J. C. C. Tsai, J. Electrochem. Soc. 124, 1107 (1977).

5. H.-J. Gossmann, F. C. Unterwald, and H. S. Luftman, J. Appl. Phys. Lett. 73, 8237 (1993).

6. Aditya Agarwal, H.-J. Gossmann, D. J. Eaglesham, L. Pelaz, S. B. Herner, D. C. Jacobson, and T. E. Haynes, manuscript in preparation for J. Appl Phys.

7. J. P. Biersack and L. G. Haggmark, Nucl. Inst. And Meth. 174, 257 (1980).

8. Aditya Agarwal, H.-J. Gossmann, D. J. Eaglesham, D. C. Jacobson, T. E. Haynes, and Yu. E. Erokhin, R. Simonton, and J. M. Poate, p. 39.1 in Proc. of the Ultra-shallow Junction Workshop, Raleigh, 1997.

9. A. Armigliato, D. Nobili, P. Ostoja, M. Servidori, S. Solmi, in Semiconductor Silicon, edited by H. R. Huff and E. Sirtl, (Electrochemical Society, 1977). 
M98004111

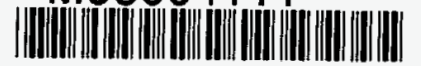

Report Number (14) GRNL/CP- 96082

CONF-980528--

Publ. Date (11) $\quad 19980503$

Sponsor Code (18) DOq/ER , XF

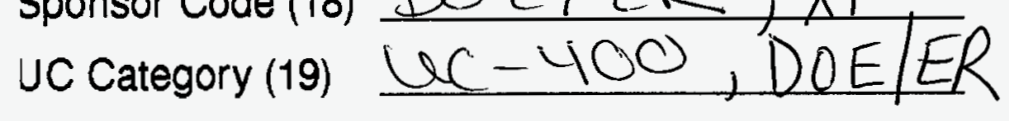

DOE 